PLASMA INSULIN AND LIVER GLYCOGEN STORAGE IN 17 RABBIT AND RAT FETUSES. A. Jost, M. Gilbert and A Kervran Iaborat Physiologie Comparée, Université Paris VI, 75005 PARIS, France.

Glycogen storage in the fetal liver obeys a hormonal control (Jost, Harvey Lect. 55:201, 1961). In rabbits it is prevented by decapitating the fetus before day 25. it is restored by giving a corticosteroid + prolactine or $\mathrm{GH}$ to the decapitate. In rats glycogen storage is prevented in fetuses decapitated on or before day 18 on condition that the mother is adrenalectomized; it is restored simply by giving a corticosteroid. It was studied whether these variations in liver glycogen are paralleled by variations in plasma immunoreactive insulin (IRI). Rabbits: fetuses decapitated on day 24 and studied day 29 (number in brackets):glycoday 24 and studied day 29 (number in brackets): glycoman standard); controls: glycogen $=26 \pm 3$ (11); IRI $=45 \pm 4$ (17) Rats:1)mother adrenalectomized on day 14, fetuses decapitated on day 18 and studied on day $21:$ glycogen= $10.0 \pm 6(8) \mathrm{mg} / \mathrm{g} ; \mathrm{IRI}=113 \pm 16(8) \mu \mathrm{U} / \mathrm{ml}$ (rat standard);2) same 100ug cortisol acetate $24 \mathrm{hr}$ before: 9 lycotreatment $+100 \mu g$ cortisol a gen $=58.4 \pm 4(10) ; I R I=95 \pm 29(10) ; 3)$ controls:glycogen $=$
$91.3 \pm 2(4) ; I R I=138 \pm 21(16)$. The striking differences in liver glycogen are not paralleled by similar variations in plasma insulin. If insulin is required for glycogen deposition in the liver, it

ting factor in decapitated fetuses.

SOMATOMEDIN ACTIVITY IN THE HUMAN HEPATIC VEIN.

18 F. Girard, R, M. Schimpff, C. Lassare, M. Donnadieu. Hop. Trousseau, Paris $12 \mathrm{e}$, France.

Blood samples were taken simultaneously from the humeral artery (H.A.) and the hepatic vein (H.V.) of 7 male adults 35 Somatomedin (SM) activity was measured by the incorporation of ${ }^{35} \mathrm{~S}$ into enbryonic chick cartilage, and growth hormone assayed by radio immunology. In 9 out of 10 cases the concentration of SM in the hepatic venal blood was found to be superior to that in the arte$\mathrm{rial}$ blood. The mean of the differences in SM activity (H.V. $-H$.
was $+0,29-0.10$ (standard error) units/ml. This difference is significant. In these conditions, the hepatic venal blood yielded SM activity $47 \%$ \& $16 \%$ higher than that in the humeral artery. a SM activity $47 \%$ In the 3 cases where a second pair of samples were taken 20 or 40 minutes after the first, a similar difference was observed. How-
ever, in the 11 subjects tested for growth hormone, no significant difference was found between the concentration of growth hormone in the 2 types of blood. The observation of high SM levels in the efferent blood of the liver tends support to the experimental findings of McConahey who proposed the, liver as the site of SM production. However, taking into consideration the hepatic plasma into consideration the hepatic plasme flow (measured in 3 cases $Q=0.810 \mathrm{l} / \mathrm{min}$ ) the importance of the differences observed must be regarded as questionable, since these
would imply a very large production of SM. In this respect, the measured SM activity has to be discussed.

19 IN SEVERELY MALNOURISHED CHILDREN

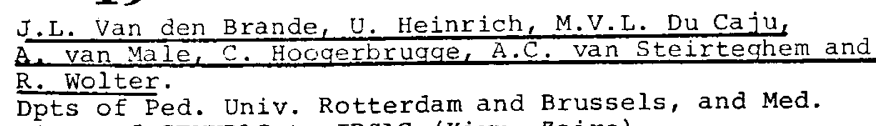

Dpts of Ped. Univ, Rotterdam and Brussels, and Med. Miss. of CEMUBAC to IRSAC (Kivu, Zaire).

In 13 patients with marasmus or kwashiorkor, plasma SM was measured using the porcine costal cartilage assay. Non-parallelism (N.P.) due to a shallow slope prevented in many samples. Results: SMted quantitation in many sample $5.20<x<.50: 3$. distribution: on admission $\leqslant .20: 5$; $.20<x$ of treatment: $.50<\mathrm{x}<.80: 2$, N.P.:3. After $4-6$ weeks of treatmen low: 6 , normal: 1 , N.P. : 3 ( 3 had died, all with initial $\mathrm{SM}<.20$ ). After $8-10$ weeks: low: 3 , normal or lama 3 untreated patients with the standard lowered its apparent potency with 35,67 and 08 resp. Heating plasma after acidification increased its poHeating plasma after acidification increased its Dotency relative to a standard control from $<.12$ to .65 sM-inhibiting material is present in plasma, initially persisting during treatment. This may contribute to the problems in reverting these chilaren from a katabolic to an anabolic state.
STUDIES ON SOMATOMEDIN IN NEWBORN AND ITS RELATIONSHIP

20 TO THE EXCRETION OF GROWTH HORMONE IN URINE.

K. W. Kastrup, H. H. Andersen. Childrens Hospital, Fuglebakken, Copenhagen.

Somatomedin (SM) was determined in cord blood and maternal blood with the chick embryo assay. The ratio cord blood/maternal blood with the chick embryo assay. The ratio cord blood/maternal blood 0.90 . Synchronous variations between the paired samples could be demonstrated suggesting a placental transfer. In prematures low values around 0.30 units SM was found in the first days of 1 ife, within 6 days the values were in the range for normal infants - 6 months of age. In mature infants initial values about 0.70 units SM was found to be within normal range after 6 days of life. Growth hormone excretion in the urine was deterdays of life. Growth hormone excretion in the urine was deterfound in the first 3 days of life i.e. more than $1000 \mathrm{ng} / 100 \mathrm{ml}$. After 6 days excretion of $100-1000 \mathrm{ng} / 100 \mathrm{ml}$ was found. In matures the initial excretion in the range of $500 \mathrm{ng} / 100 \mathrm{ml}$ decreased to less than $100 \mathrm{ng} / 100 \mathrm{ml}$ in one week. The high excretion in prematures is related to impaired renal function but also repreprematures is related to impaired renal function but also repreproduction of growth hormone in the first days of life is related to generation of SM in the newborn.

\section{1 STUDIES ON HUMAN PLASMA SOMATOMEDIN ACTIVITY IN THE NFONATAL PERIOD In} Unité de Recherche sur les Maladies du Métabolisme chez l'Enfant Hôpital des Enfants Malades, Paris, FRANCE.

Plasma Somatomedin activity (SM) was measured in nomal newborns by the porcine rib cartilage assay according to van den Brande and Du Caju. Results were expressed as potency ratio related to an adult reference standard. The mean SM in mothers at delivery ( $n=14$ ) was $0.26 \pm 0.19$ (SD), range $0.10-0.83$, and was higher ( $p<0,01$ ) in cord blood $(n=14) 0.54 \pm 0.33$, range $0.10-1.32$ In newborns aged from 2 to 10 hours SM was not detectable in 3 individual sanples and five pools of plasma. In 3 others cases SM was respectively $0.14,0.26$ and 0.42 . The mean SM increased on day 4 and $5(0.98 \pm 0.46$, rainge 0.43 to 1.55$)$ in six infants. After the age of one month the mean SM was $0.42 \pm 0.24$, range $0.10-0.89$. No in vitro inhibitory effect could be demonstrated in plasmas with low SM activities.

These variations in SM might be due to the early decrease in plasma oestradiol and to the later diminution in circulating GH.

\section{2} AGE-DEPENDENT VARIATION IN CARTILAGE RESPONSE TO G.R.Beaton and V. Singh

Department of Physiology, University of the Witwatersrand, Medical School, Johannesburg, South Africa, 2001.

The role of variation in end-organ cartilage response to somatomedin (SM) as a significant determinant of growth velocity has been investigated.

The response of costal cartilage of foetal and post-natal rabbits to SM has been assessed by simultaneously measuring ${ }^{35} \mathrm{~S}$ and ${ }^{3} \mathrm{H}$-thymidine uptake in vitro. Cartilage from rabbits of known growth rate at 23 and 30 days after conception (gestation 33 days), and at $1,7,17,28,39,64,90$ and more than 200 days after birth, was studied. An excellent than 200 days after birth, was studied. An excellent of the costal cartilage was shown. The uptake of ${ }^{35} \mathrm{~S}$ was also closely related to growth velocity and the ${ }^{3} \mathrm{H} /{ }^{35} \mathrm{~S}$ ratio declined as growth rate slowed.

Serum SM of each age group was measured by the porcine cartilage technique of Van den Brande. The post-natal serum SM increased progressively with age to an adult plateau.

This study suggests that the growth velocity of costal cartilage is determined by the combined effects of end-organ response and serum SM stimulus. 